\title{
New reports on secretory structures of vegetative and floral organs of Hypericum elodes (Hypericaceae)
}

\author{
Vieira da Silva, I. , Nogueira, T. ${ }^{* *}$ and Ascensão, L. ${ }^{*}$
}

* Departamento de Biologia Vegetal, Universidade de Lisboa, Faculdade de Ciências, IBB, Centro de Biotecnologia Vegetal, Campo Grande, 1749-016 Lisboa, PORTUGAL

** Laboratório Nacional de Energia e Geologia, I.P. (LNEG), Estrada do Paço do Lumiar, 22, 1649-038 Lisboa. PORTUGAL

\section{Email: lia.ascensao@fc.ul.pt}

Hypericum elodes L. (Hypericaceae), commonly known as marsh St. John's wort, is one of the fourteen species found spontaneously in Portugal and it is endemic of Europe. It occurs in acidic waterlogged grounds in the Norwest of Portugal and in the Azores islands, Pico and São Miguel [1]. In the last decades intense phytochemical and pharmacological research have been performed in Hypericum species, namely in $H$. perforatum, the most studied species of the genus and traditionally used as a medicinal plant. Its bioactive secondary metabolites, naphtodianthrones (e.g. hypericin and pseudohypericin), phloroglucinols (e.g. hyperforin), bioflavonoids and xanthones have been widely studied for their anti-depressant, anti-microbial, anti-viral and anti-proliferative properties [2]. Despite the abundant phytochemical reports available in Hypericum species, the morpho-anatomical studies are scarce and fragmented [3-6]. The present study, included in an ongoing project on Hypericum glands, aims to provide new data on the morphology and anatomy of the secretory structures of $H$. elodes. Although these glands were previously studied in specimens grown in Italy [5], in the current study we describe in detail their morphology, distribution and histochemistry on the vegetative and floral organs.

Small branches of $H$. elodes were collected from populations occurring in Portugal and samples of leaves and flowers, at different stages of development, were fixed with glutaraldehyde and prepared for scanning electron microscopy or embedding in Leica Historesin ${ }^{\circledR}$, following standard methods. Additionally, the main classes of compounds present in the secretion were histochemically characterized.

Five different types of secretory structures are observed in H. elodes (idioblasts, type A and B ducts, translucent glands and peduncular black nodules). Idioblasts, secretory single cells, are frequent in the epidermis and in the ground parenchyma of all organs. Type A ducts, with a narrow lumen always delimited by four secretory thin-walled cells, are found in association with the phloem in stems, leaves, bracts, sepals and petals (Fig. 1A, B). Type B ducts, with a wider lumen surrounded in general by ten cells, are located in bracts, sepals and ovary wall (Fig. 1G, H). Translucent glands, round cavities delimited by one epithelial cell layer, occur close to the upper epidermis of the leaf, distributed intervein areas without any connection with vascular bundles (Fig.1C, D). A stipitate translucent gland is also observed inside an ellipsoidal protuberance located over the connective, between anther lobes (Fig. 1G, I). Peduncular black nodules, glandular emergences showing in vivo a characteristic reddish color, are present on the margins of bracts and sepals (Fig. 1E, F). On the top of the glandular head of peduncular black nodules an apical pore, formed by cell disruption, allows the secretion release (Fig. 1F). Histochemical reactions showed that idioblasts synthesize and accumulate tannins, ducts secrete oleoresins and translucent glands produce essential oils and flavonolic aglycones. The red color of the peduncular black nodules is due to the presence of hypericin.

Although the present study confirms the diversity of secretory structures previously reported in H. elodes [6], we didn't find type $\mathrm{C}$ ducts nor detected alkaloids in any organ. Moreover, we consider that the head of the glandular emergences, consisting of a cluster of secretory cells, are true black nodules. The apical pore to 
discharge the secretion could be due to external factors, such as extreme climatic conditions or mechanical damage, but further research is needed to support this interpretation.

The authors acknowledge the funding by Fundação para a Ciência e Tecnologia through the project FCT PEst-OE/EQB/LA0023/2011.

\section{References}

[1] Franco, J.A., Nova Flora de Portugal (Continente e Açores), 1, 447-453, 1971.

[2] Crockett, S.L. and Robson, N.B., Medicinal Aromatic Plant Sci. Biotech., 5, 1-13, 2011.

[3] Ciccarelli, D. et al., Isr. J. Plant Sci., 49, 33-40, 2001 a.

[4] Ciccarelli, D. et al., Ann. Bot., 88, 637-644, 2001 b.

[5] Bottega, S. et al., Isr. J. Plant Sci., 52, 51-57, 2004.

[6] Lotocka, B. and Osinska, E., Bot. J. Lin. Soc., 163, 70-86, 2010.

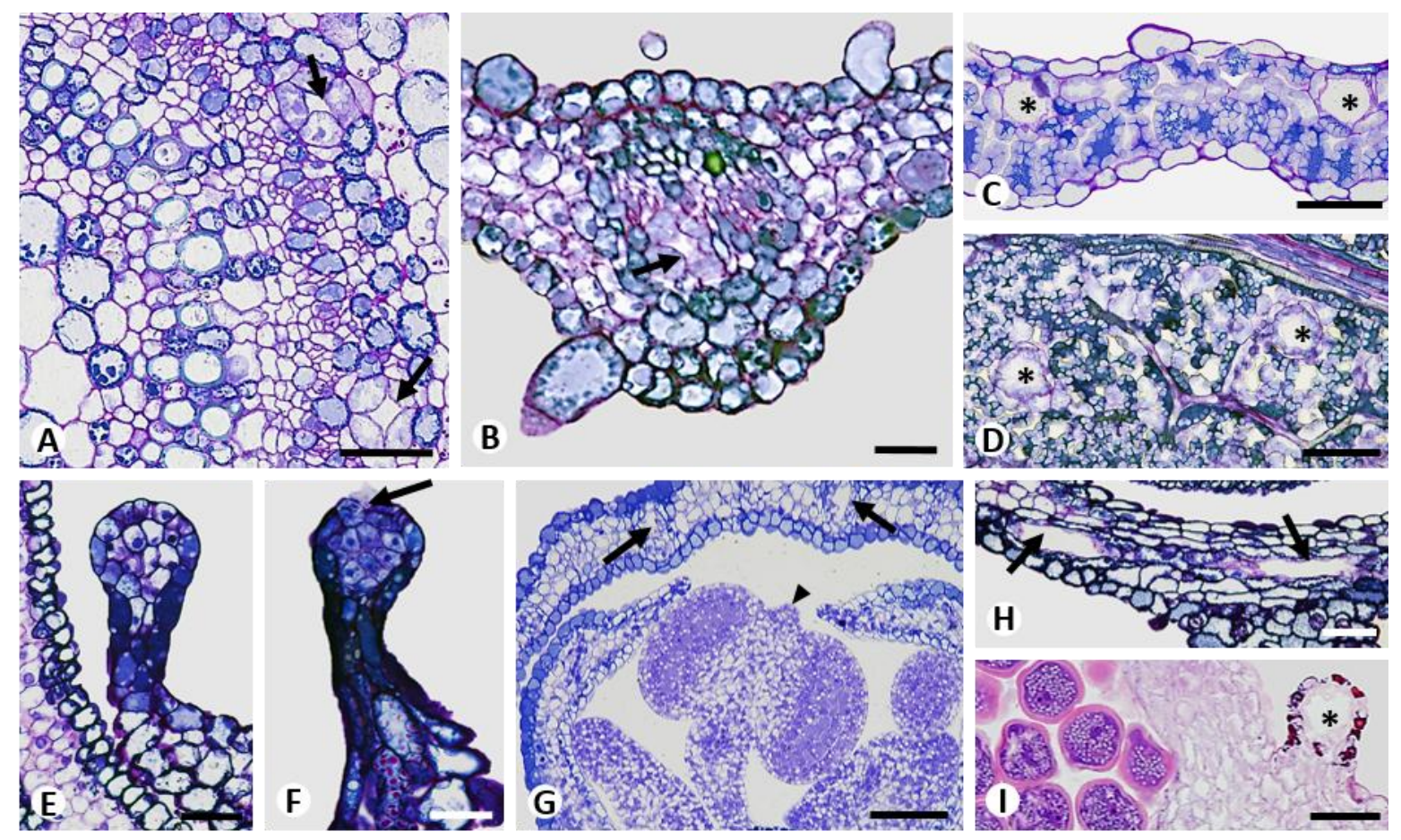

Figure 1 - Secretory structures in H. elodes organs. Light micrographs of historesin sections stained with PAS reagent/Toluidine Blue O. A, B, Stem and sepal cross sections showing type A ducts (arrows). C, D, Translucent glands (asterisks) in a cross and paradermal leaf section, respectively. E, F, Peduncular black nodules at sepal margins. Cell disruption (arrow) is clearly seen on the glandular head. G, Longitudinal section of a young bud showing type B ducts (arrows) and the ellipsoidal glandular protuberance (arrowhead) between anther lobes, over the connective. H, Type B ducts (arrows) in a longitudinal section of a sepal. I, Portion of an anther showing the stipitate translucent gland (asterisk). Bars $=50 \mu \mathrm{m}(\mathrm{A}, \mathrm{C}, \mathrm{D}$ and I); $25 \mu \mathrm{m}(\mathrm{B}, \mathrm{E}, \mathrm{F})$ and $100 \mu \mathrm{m}(\mathrm{G}$ and $\mathrm{H})$. 